KAOLINITE DEHYDROXYLATION STUDIES

ON CUMPAC' ' SPECIMEINS

\title{
Gautam Bandyopadhyay
}

(M.S. Thesis)

December 1970

AEC Contract No. W-7405-eng-48

THIS DOCUMENT CONFIRMED AS UNCLASSIFIED DIVISION OF CLASSIFICATION BY OHKahnlamh DATE

$3|12| 71$

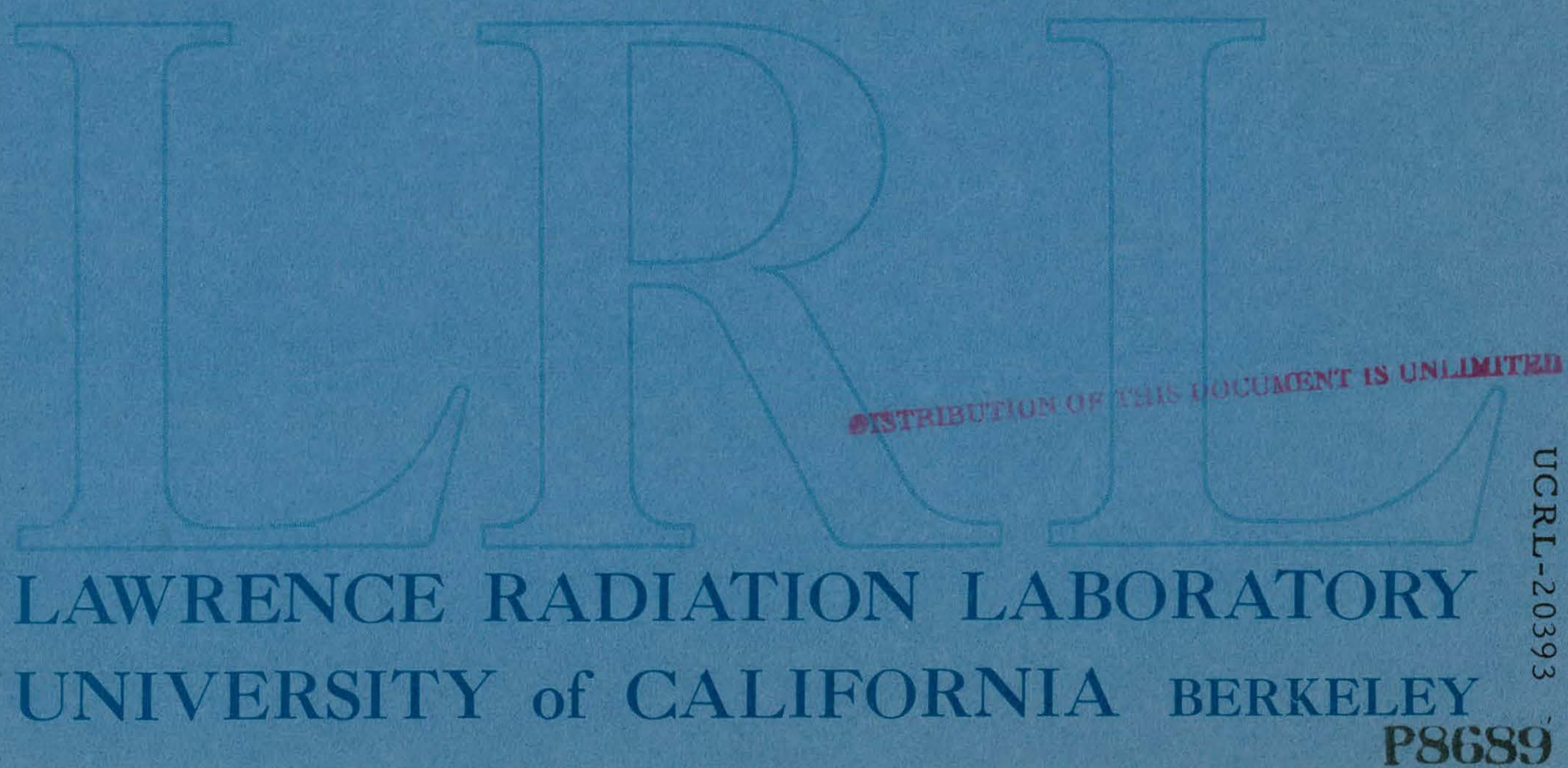




\section{DISCLAIMER}

This report was prepared as an account of work sponsored by an agency of the United States Government. Neither the United States Government nor any agency Thereof, nor any of their employees, makes any warranty, express or implied, or assumes any legal liability or responsibility for the accuracy, completeness, or usefulness of any information, apparatus, product, or process disclosed, or represents that its use would not infringe privately owned rights. Reference herein to any specific commercial product, process, or service by trade name, trademark, manufacturer, or otherwise does not necessarily constitute or imply its endorsement, recommendation, or favoring by the United States Government or any agency thereof. The views and opinions of authors expressed herein do not necessarily state or reflect those of the United States Government or any agency thereof. 


\section{DISCLAIMER}

Portions of this document may be illegible in electronic image products. Images are produced from the best available original document. 


\section{PAGES $\mathrm{i}$ to $\mathrm{ii}$ WERE INTENTIONALLY LEFT BLANK}


KAOLINITE DEHYDROXYLATION STUDIES

ON COMPACT SPECIMENS

\section{Contents}

ABSTRACT . V V

I. INTRODUCTION ' 1

$\begin{array}{ll}\text { II. EXPERIMENTAL PROCEDURE } & 7\end{array}$

A. Materials 7

B. Sample Preparation $\quad 1,7$

C. Gradient Firing Experiments 8

D. Thermogravimetric Analysis (TGA) 10

III. RESULTS AND DISCUSSION 11

A. Importance of Bulk Density and Thermal Gradient in Gradient Firing

B. Importance of Back Pressure and Porosity on TGA Experiments

C. Effect of Dilution of Clay Specimens with Inert Alumina $\quad 22$

D. Mechanism 27

IV. SUMMARY AND CONCLUSION 32

ACKNOWLEDGMENT T $\quad \therefore \quad 34$

REFERENCES sponsored by the United States Government. Neither the United States nor the United States Atomic Energy Commission, nor any of their employees, nor any of their contractors, subcontractors, or their employees, makes any warranty, express or implied, or assumes any legal liability or. responsibility for the accuracy, completeness or usefulness of any information, apparatus, product or process disclosed, or represents that its use would not infringe privately owned rights. 


\section{THIS PAGE \\ WAS INTENTIONALLY \\ LEFT BLANK}




\title{
KAOLINITE DEHYDROXYLATION STUDIES \\ ON COMPACT SPECIMENS
}

\section{Gautam Bandyopadhyay}

\section{Inorganic Materials Research Division, Lawrence Radiation Laboratory, and Department of Materials Science and Engineering, College of Engineering, University of Califormia, Berkeley, California}

\begin{abstract}
Kaolinite dehydroxylation reaction on compact specimens has been studied by gradient firing technique and thermogravimetric analysis. Gradient firing technique is a new analyzing method, where the main contril is a fixed temperature gradient through the specimens. In botlt these methods, the reaction rate was found to be determined by a combined effect of permeability and water vapor pressure gradient. through the body. It has been further shown that two different slow steps, namely permeation and the reaction step, may control the dehydroxylation process depending on the porosity, temperature of the reaction, and the total amount of water present in the body.
\end{abstract}




\section{INTRODUCTION}

Firing is an important step in ceramic processing. During this operation, in many cases, thermal reactions and decomposition take place. For example, during firing operation in brick industries, evolution of white smoke indicates the decomposition of various clay minerals to produce water vapor. It is essential to control the firing conditions at this decomposition stage and is usually controlled by shutting off the furnace temporarily. Clays are used in various ceramic industries, such as in brick, whiteware, pottery, and electrical porcelain industries. Kaolin clay, which predominantly consists of kaolinite, is one of the most widely used clays. Kaolinite dehydrates to an amorphous material "metakaolin" at about $550^{\circ} \mathrm{C}$ according to the reaction:

$$
\mathrm{Al}_{2} \mathrm{O}_{3} \cdot 2 \mathrm{SiO}_{2} \cdot 2 \mathrm{H}_{2} \mathrm{O}=\mathrm{Al}_{2} \mathrm{O}_{3} \cdot 2 \mathrm{SiO}_{2}+2 \mathrm{H}_{2} \mathrm{O}
$$

Although the above reaction has been expressed as a reversible one, the reverse reaction of rehydration requires considerable water vapor pressure at temperatures not exceeding about $400^{\circ} \mathrm{C}$ in order to reconstitute crystalline kaolinite in a relatively short period. ${ }^{1}$ Previous studies $^{2-6}$ have shown that the above reaction is extremely sensitive to the water vapor pressure. This fact would have pronounced effect on firing and should be considered in the firing operation. The main parameters during firing are temperature of the system, heating schedule, time at temperature, the gas environment and the partial pressures of the gaseous components in the immediate vicinity of the ceramic ware. In order to know the proper firing conditions, the basic mechanism of 
reactions taking place during firing should be known. The present work deals with the firing of kaolinite clay because of its importance in various ceramic industries.

The kaolinite dehydroxylation reaction has been studied extensively by the thermogravimetric analysis (TGA) and by differential thermal analysis (DMA). Previous studies recognize the fact that the best conditions for studying the dehydroxylation reaction are, to use loosely compact opccimcns ${ }^{2-5,7}$ and a low reucliun temperature, ${ }^{5}$ a.s hoth of these avoid some of the complexities of the reaction. Unfortunately, in industries, loosely cumpacl spectmens are rarely used and as the comaction of the body affects the reaction rate considerably, studies on compact specimens would be a better approach to understand the firing process when dehydroxylation occurs.

Most of the previous workers ${ }^{2-5,7}$ reported that the dehydroxylation of kaolinite followo a first older reacliun klnetles, that is, $n=1$ in the equation

$$
-\frac{d c}{d t}=k \cdot c^{n}
$$

Where $\mathrm{c}=$ concentration, $t=$ time, $k=$ rate constant, and $n=$ order of reaction. Weber and Roy $^{8}$ analyzed their data in terms of this equation and reported values of $\mathrm{n}$ from less than 1 to 3 .

Brindley and Nakahira ${ }^{3}$ found that the reaction only approximately followed first order kinetics. They furthermore pointed out the marked dependence of rate constants, determined from isothermal weight loss measurements, on specimen size, shape and compaction. They experimented 
with a series of discs of kaolinite of constant diameter but of differing thickness, and reported that the rate constant was inversely proportional to the specimen thickness:

$$
1 / k=a+b x
$$

where $k$ is the rate constant, $x$ is the specimen thickness and $a$ and $b$ are constants. In this way they obtained a $\mathrm{k}$ value for an infinitely thin disc by extrapolation. It was further pointed out that by this method the influence of accumulation of water within the sample covid be neglected: Evans and White ${ }^{4}$ also pointed to the importance of specimen size, shape, and compaction. They showed that a loosely packed specimen more nearly followed a first order kinetics.

Although Brindley and Nakahira ${ }^{2,3}$ and Evans and White ${ }^{4}$ discussed the importance of water vapor on the kaolinite dehydroxylation reaction, Holt et al. 6 for the first time used controlled water vapor pressure to study the kinetics of the reaction. They showed that at low vapor pressures, percent dehydroxylation and time have a "simple parabolic relation consistent with a diffusion process through an increasingly developing product layer."

$$
D_{1}(\alpha)=\alpha^{2}=k_{1} t
$$

where $\alpha$ is percent reacted, $t$ is time and $k_{l}$ is a constant involving a diffusion coefficlent, which is treated as a material constant and. which does not change as the reaction proceeds. This equation may be 
obtained directly from the Fick's law or from the fact that the rate of reaction $\frac{d \alpha}{d t}$ is inversely proportional to $\frac{1}{\alpha}$. It may be applicable to the dehydroxylation of kaolinite if the reaction proceeds mainly in the direction normal to $(001)$. But according to Brindley et al. 9 probably diffusion parallel to the plates is easier as it does not require water to pass through the $\mathrm{Al}_{2} \mathrm{O}_{3} \bullet \mathrm{SiO}_{2}$ framework and "in this case a cylindrical model with radial diffusion and constant flux of the diffusing species may be morc appropriule." Holt et a.l. derived the equation

$$
D_{2}(\alpha)=(1-\alpha) \text { in }(1-\alpha)+\alpha=k_{2} t
$$

The corresponding equation for a reacting sphere has been given by various authors ${ }^{10,11}$ and can be written f.a

$$
D_{3}(\alpha)=\left(1-\frac{2 \alpha}{3}\right)-(1-\alpha)^{2 / 3}=k_{3} \cdot t
$$

$k_{2}$ and $k_{3}$ are some sort of constents as $k_{1}$ is.

Brinaley et w. 9 reported that Ei ther Eq. (4) or Eq. (5) gives best fit to their data although the data points deviate at $=0.6$. They also tried to fit their data in the equation

$$
F(\alpha)=-\ln (1-\alpha)=k \cdot t
$$

in the $\alpha$ vs $t / t_{0.5}$ plot and found that this equation does not agree in any way with the actual plot. Thus they ruled out the idea of first order kinetics. To justify this fact they furthermore reported that 
the diffusion equations could be approximately expressed in the form

$$
-\ln (1-\alpha)=k_{0}+k \cdot t
$$

for sufficiently large values of $t$ and only linear relation between $\log (1-\alpha)$ and $t$ is not sufficient for first order kinetics, but the line should also pass through the point $\alpha=0$ at $t=0$. Thus determining the effective starting time of the reaction becomes very important.

Although apparently Eqs. (3), (4) and (5) look very different from each other, when $\alpha$ is plotted against $t / t_{0.5}$, it is virtually impossible to distinguish between the three mechanisms unless the decomposition is more than $70 \%$ complete and a good fit up to $100 \%$ is obtained. 10,11 Johnson and Kessler ${ }^{12}$ included the effect of particle size distribution in their kinetics study and observed that their results did not fit diffusion and phase-boundary controlled reactions in the radial direction. From the observation of particle thickness dependence they concluded that "the reaction appears to proceed through the kaoline particles by a pseudo-phase-boundary controlled mechanism, principally in the [100] direction." The rate was found to be proportional to the surface area.

In the present study, unlike the specimens used by previous workers, relatively large comact samples have been used for studying the effect of apparent density, thermal gradient, and dilution of clay specimens with inert materials on the dehydroxylation reaction kinetics. A technique, developed by Fulrath ${ }^{13}$ about 15 years ago in this laboratory and termed as "thermal gradient firing," has been used along with the TGA. 
Thermal gradient firing has been a standard laboratory experiment for the undergraduate students in Ceramic Engineering at the University of California, Berkeley, since 1960. Recently Orton Foundation has developed a sinilar system known as "Orton Thermal Analyzer" based on the more or less similar principles. 14 The main control in the gradient firing method is a fixed temperature gradient between the center of the sample and the furnace air temperature. Two thermocouples, one inserted at the center of the sample and another kept in the furnace air, weje connected differentially. Power supply to the furnace was controllid automatically, to maintain a fixed temperature gradient. Thus the technique takes care of the heating schedule without allowing the tlermal gradient to change from the set value and also it indicates the endrthermic and exothermic effects within the specimen without the need for inert references of comparison. Here an attempt has been made to compare the results obtained from gradient firing experiments with those obtained from IIGA runs, and thus to get some insight to the actual processes going on during the reaction. 


\section{EXPERIMENTAL PROCEDURE}

\section{A. Materials}

Commercial D. R. G. Clay and A-14 alumina were used for preparation of various specimens. X-ray and D.T.A. analysis showed that the Georgia Kaolin did not have any detectable accessory minerals associated with the well crystallized kaolinite.

\section{B. Sample Preparation}

The clay powder was mixed with $4 \%$ water (by wt.) in a Hubert mixer. Then varying weights ( 15 to 20 gs) of clay were pressed in a steel die to a constant volume. Samples weighing less than 15 gs were too light to hold the structure, whereas those weighing more than 20 gs were too dense to make a proper sample. Thus the range between $15 \mathrm{gs}$ and $20 \mathrm{gs}$ was selected. The size of the cylindrical specimens ( $I^{\prime \prime} \times I^{\prime \prime}$ ) was controlled carefully to have a better control on the bulk density of the sample. In order to place the thermocouple in the sample in the gradient runs, specimens were drilled carefully at the mid-point along the axis of the cylinder.

Amongst the varying bulk density specimens $18 \mathrm{gs}$ sample was found to be the best to work with. Thus for all constant bulk density runs, 18 gs samples were used as the standard.

In order to control the permeation of water vapor through the clay mass, some specimens were prepared by replacing a part of the clay with an equal volume of inert alumina. The porosity in all the clay-alumina specimens was always constant and was equal to that of the 18 gs $100 \%$ kaolin specimen. Weighed amounts of alumina were first milled for four hours along with water in an alumina lined ball mill. Then clay was 
added and milling was continued for another half hour. The mix was then dried at $100^{\circ} \mathrm{C}$, passed through U.S. 40 sieves, mixed with $4 \%$ water in the Hubert mixer and used for specimen preparation.

\section{Grèdient Firing Experiments}

The main control for the process for a fixed temperature gradient between the center of the sample and the furnace air. Two thermocouples, one inserted at the center of the sample and another in the furnace air were connected differentially. Power supply to the furmare was controlled automatically once the necessary gradient was set. One other thermocouple was used to measure the furnace air temperature. Power supply to the furnace was also recorded in some runs. Figure 1 shows the important aspects of the apparatus set up. A platinum would cylindrical furnace 10" long and 2" I.D. was used.

The specimens were placed on the center thermocouple and the power was turned on. When the system attained the necessary thermal gradient, it was switched on to the automatic control. Thus the set thermal gradient was maintained constant throughout the run and the heating schedule was determined by the thermal gradient itself.

For determining the amoumt of weight lost during such a gradient run, a number of specimens of same weight and composition were taken. These specimens were then heated for various times in the gradient experiments and weighed immediately afterwards, after switching off the furnace. Weights lost during the times, the arrest portion just starts and just ends, were noted to determine the amount of water lost at the arrest position ( $W_{\text {arrest }}$ ). To avoid error in determining the value of time at arrest ( $\left.t_{\text {arrest }}\right)$, the time to move through the temperature 


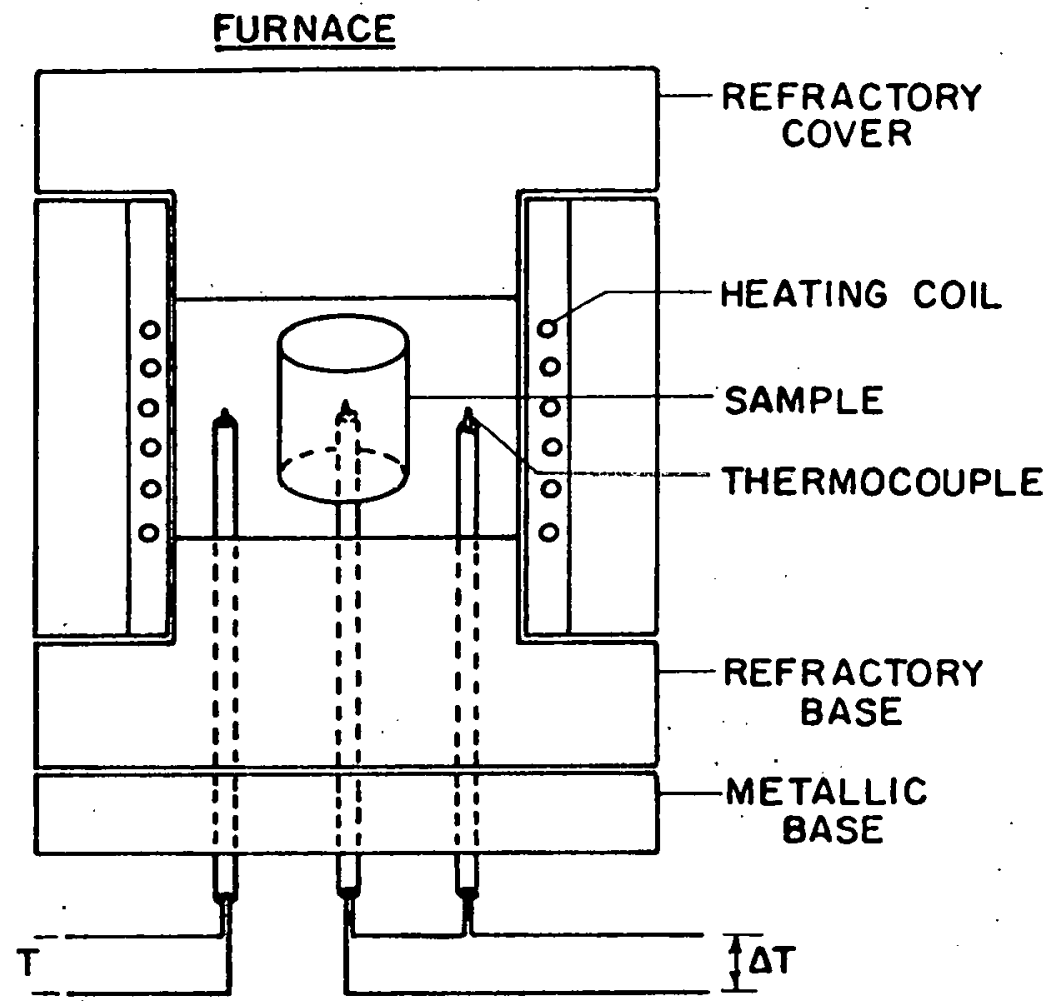

a) SAMPLE AND THERMCOUPLE POSITIONS IN THE FURNACE.

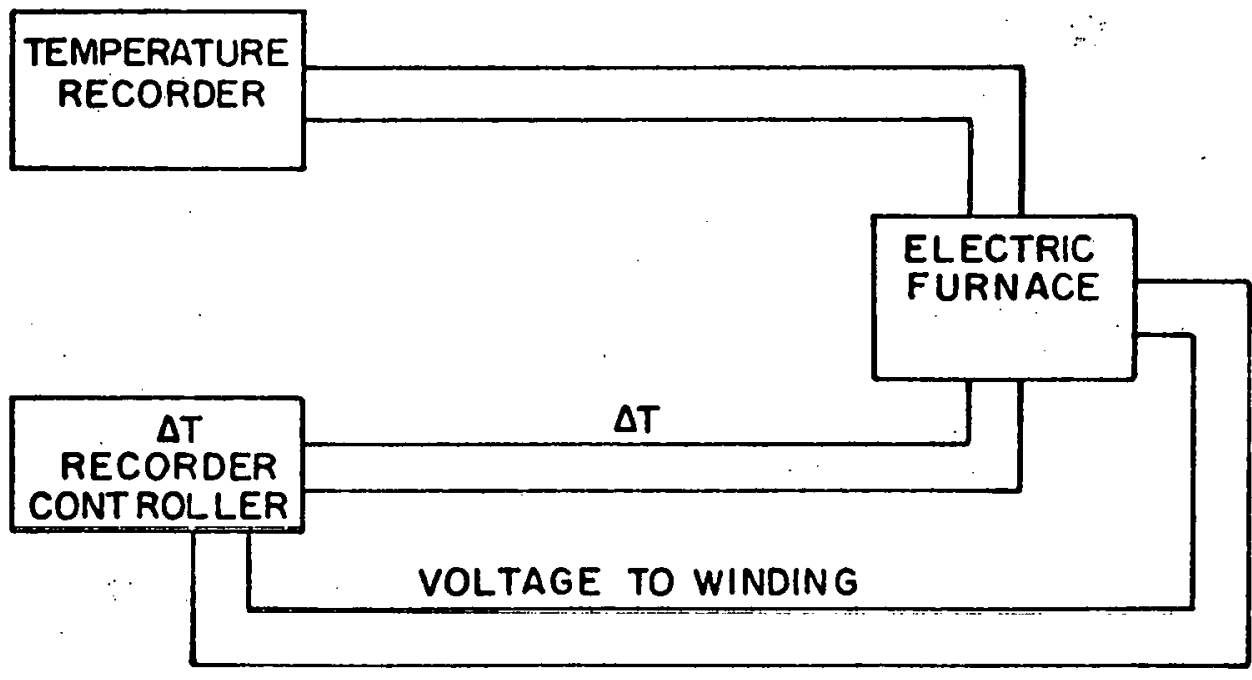

b) SCHEMATIC DIAGRAM 


$$
\left(\mathrm{T}_{\text {arrest }}-20^{\circ} \mathrm{C}\right) \text { and }\left(\mathrm{T}_{\text {arrest }}+20^{\circ} \mathrm{C}\right) \text { was taken as } \mathrm{t}_{\text {arrest }}
$$

In a few runs, the temperature of the furnace was quickly brought to $500^{\circ} \mathrm{C}$ and was maintained constant. The variation thermal gradient was recorded.

\section{Thermogravimetric Analysis (TGA)}

The weight loss experiment was conducted in air with the weight change recorded continuously. The cylindriral. sperimen contained in a platinum buckct was suspended frü a platinum wire which was connerter to one arm of the microbalance into a Kanthal wound tube furnace. A control thermocuuple was kepl at the hottest part of the furnace and the temperature was controlled by the use of a proportioned controller. In all TGA runs the temperature was very quickly brought to $500^{\circ} \mathrm{C}$ and was then maintained constant. After sufficient time of reaction, the temperature was raised to $900^{\circ} \mathrm{C}$ at the rate of $12^{\circ} \mathrm{C} / \mathrm{min}$ and then was kept at that temperature for half an hour during which the last traces of water were removed. Then the samples were weighed. After cooling the furnace, cold weight of the specimens was also taken. Thus knowing the total amount of water present in the specimen, fraction weight lost (or water lost) at various times were calculated. 


\section{RESULTS AND DISCUSSION}

There are two diffusion processes occuring during the kaolinite dehydroxylation reaction. Tussaint et al. ${ }^{5}$ termed these two as "inner diffusion" and "gross diffusion." The first kind is the diffusion of nucleated water inside the individual kaolinite particles, whereas the later one means permeation of water vapor through the pore structure of the compact of clay particles. The first diffusion process is determined by the crystalline properties, while partial vapor pressure of water and also the porosity of the body affects the gross diffusion process.

For the large compact bodies, as used in the present study, gros's diffusion is expected to be quite important. Because of the large size of the specimens, thermal gradient in the body also becomes relatively important. Figure 2 shows the general nature of the plots obtained for kaolinite dehydroxylation reaction in the gradient firing runs. The enothermic reaction at $960^{\circ} \mathrm{C}$ has not been shown in the plot.

A. Importance of Bulk Density and Thermal Gradient in Gradient Firing

The important observations. made froin Fig. 2 and Fig. 3 are:

(1) Arrest temperature in the gradient run increases when

(i) bulk density increases, thermal gradient remaining constant (Figs. 2 and 3).

(ii) thermal gradient increases, bulk density remaining constant (Fig. 3).

(2). Higher bulk density samples dehydroxylate faster in the gradient firing runs at constant thermal gradient (Fig. 2).

To explain the above, the time-temperature plot obtained from the 


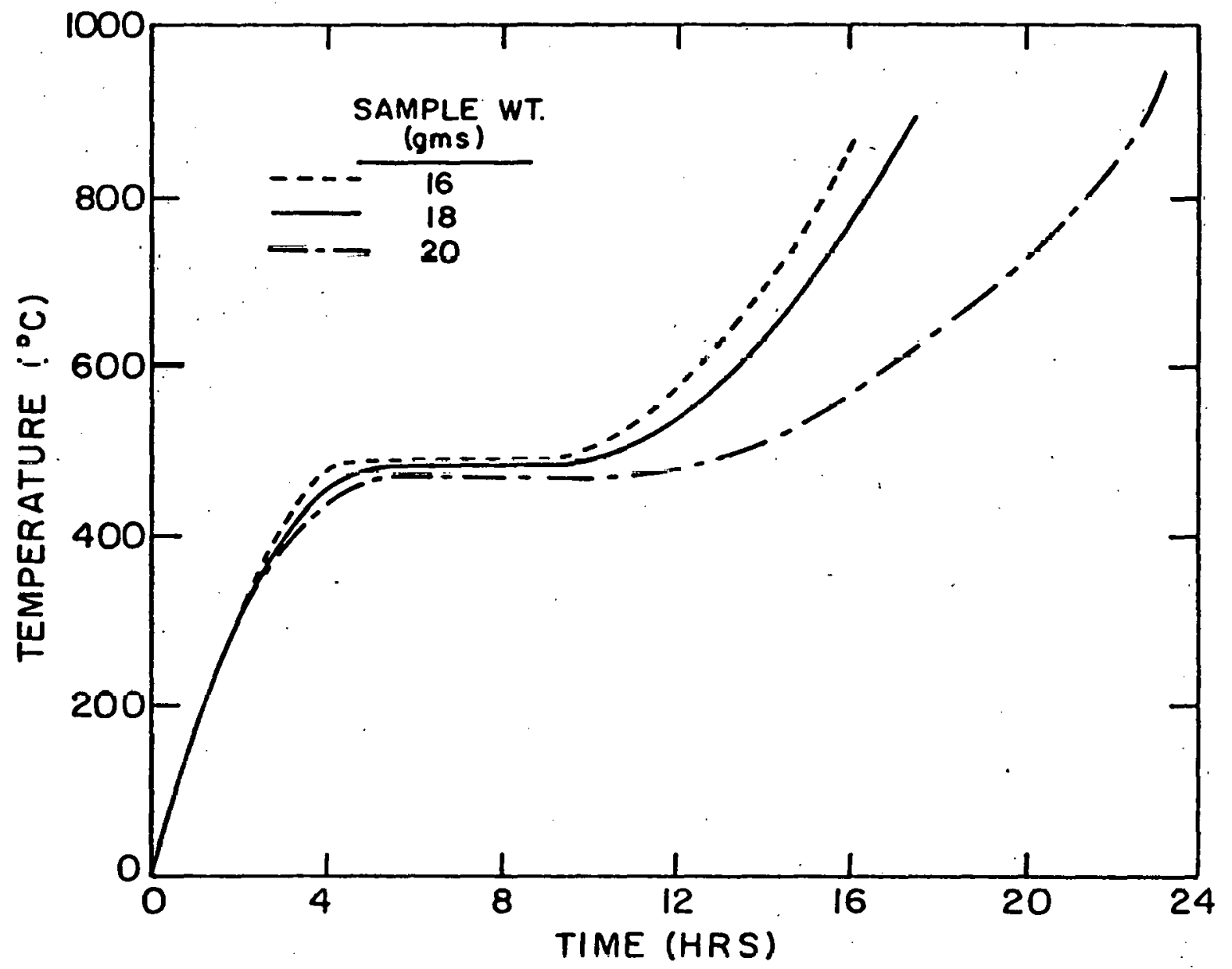

XBL $7012-7339$

- Figure 2. Gradient firing runs for varying bulk dene1ty $100 \%$ keolin specimens. Gradient was $0.15 \mathrm{mV}$. 


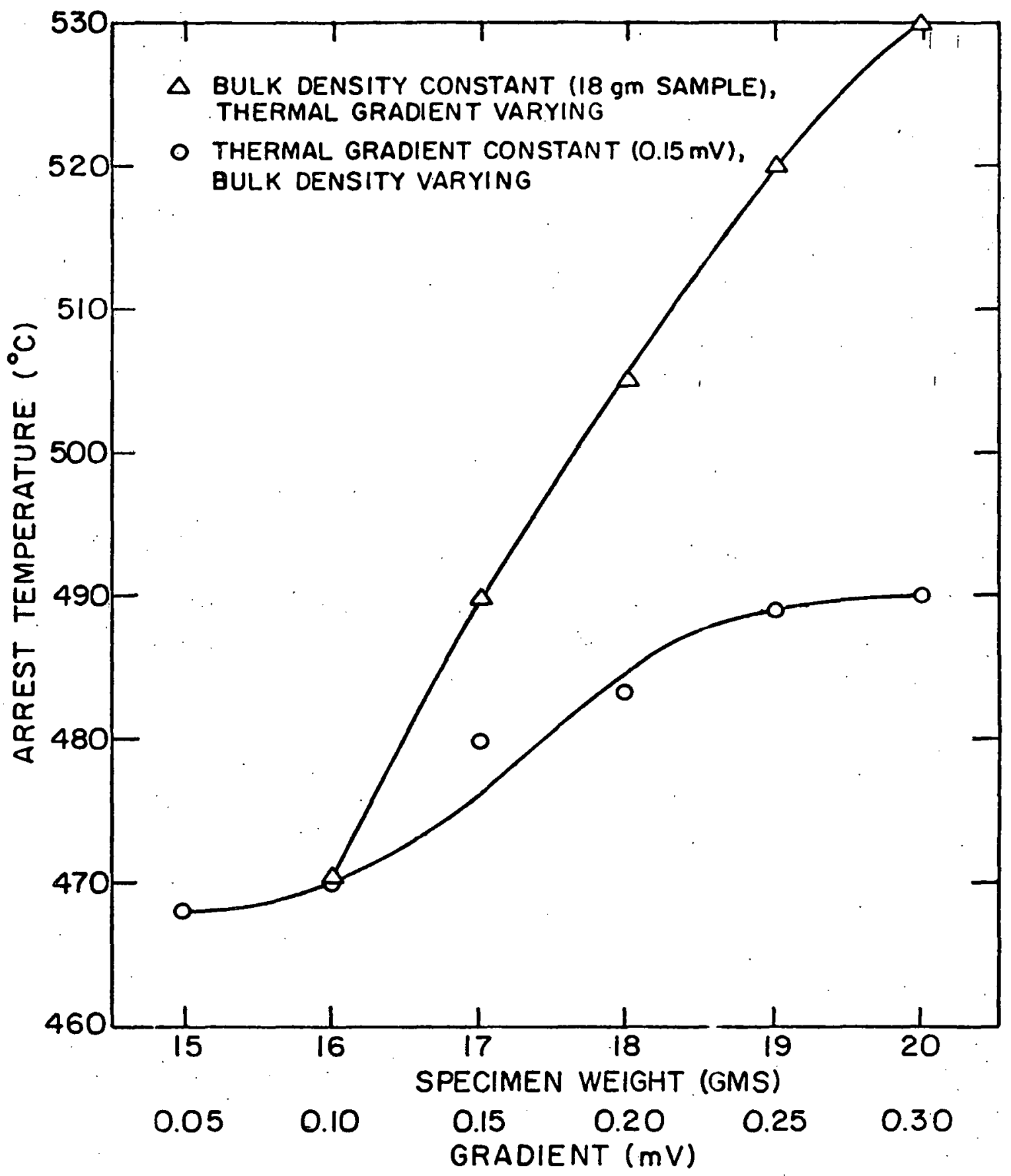

$X B L 7012-7338$

Figure 3. Variation of arrest temperature with bulk density and thermal gradient. 
gradient iling runs need to be explained step by step. Initially the plot shows a more or less straight line relationship, the slope being primarily dependent on the thermal gradient. As soon as the reaction starts, a water pressure is established within the body, termed as "back pressure" which is dependent on the porosity of the specimen and also on the temperature gradient through the body. The arrest temperature is determined by the "equilibrium back pressure" created inside the body following the vapor pressure-temperature relationchip (ClausiusClapeyron equation):

$$
\frac{\mathrm{d} \cdot \ln \mathrm{P}}{\mathrm{dT}}=\frac{\Delta \mathrm{H}}{\mathrm{RT}^{2}}
$$

The term "equilibrium back pressure" signifies the pressure created inside the body, when the amount if water vapor produced is equal to the amount of water vapor expelled irom the body, that. if, nn rquilibrium has been reached. As long as the "equilibrium back pressure" is maintained or, in other words, sufficient reaction is going on to maintain the back pressure, the center temperature remains unchanged. After that it starts to creep up again.

Permeahility for the water vopor, produest at the inluriur of the specimen, decreases with the decrease of porosity. Thus "equilibrium back pressure" and hence arrest temperature increases with the decrease of porosity. Increased thermal gradient also results in an increase of back pressure, as in that case the water vapor produced at the interior of the sample cannot permeate as easily as before for the relatively higher reaction rate and, as a result, a higher water vapor pressure is 
created in the interior of the specimen. Therefore, the arrest temperature increases with the increase of either bulk density or thermal gradient.

At this point it should be noted that the higher the arrest temperature, the higher is the average reaction rate for dehydroxylation. This is because the flux of water vapor leaving the body is higher at hi gher temperatures, thus resulting in an increased overall reaction rate. To make this statement clear, we can use the equation

$$
\frac{d w}{d t}=A \cdot K \cdot \Delta P
$$

where $\frac{d w}{d t}=$ weight lost per unit time from the body

$$
\begin{aligned}
A= & \text { a constant depending on the size of the specimen } \\
K= & \text { permeation constant depending only on the porosity of the } \\
& \text { specimen. Increases with decrease of porosity. } \\
\Delta \mathrm{P}= & \text { pressure gradient through the body. }
\end{aligned}
$$

With increasing density of the specimens, $K$ decreases. But as the . arrest temperature increases with increasing density, $\Delta \mathrm{P}$ will increase at a much faster rate ( $\Delta \mathrm{P}$ is dependent on temperature exponentially). Thus the increase in density of the specimens in the gradient firing runs shows an increase in reaction rate.

We have already noted that arrest temperature increases with the increase of thermal gradient, when same bulk density specimens were run. Assuming the veight lost during arrest portion is same in all cases, it is possible to make an Arrhenius type plot. It is interesting to note that the energy of activation calculated from the slope of the log $t$ vs 
I/T plot (Fig. 4) is $51.7 \mathrm{kcal} / \mathrm{mole}$, which is in the range calculated by the previous workers for the activation energy for kaolinite dehydroxylation.

\section{B. Importance of Back Pressure and Porcsity on TGA Experiments}

The conditions in the TGA rum are little different from those in the gradient firing runs. In the TGA experiments the temperature of the furnace was quickly brought to $500^{\circ} \mathrm{C}$, after which it was maintained constant, whereas in the Eradient firing, the set thermal gradient was actually controlling the heating schedule. It was observed that in gradient experiments porosity and thermal gradient determines the arrest temperature that sets the reaction rate for the specimen. In TGA runs, on the other hand, the temperature of the furnace is constant. Therefore, we would expect that, in this case, the porosity and the furnace temperature along with the heat flux should determine the thermal gradient, if tho came remeation controlled reaction takes place. For clarification, let us use Eq. (9)

$$
\frac{d w}{d t}=A \cdot K \cdot \Lambda P
$$

It is to be noted that in the right hand side of Eq. (9), both $K$ and $\Delta P$ may vary with the bulk density of the specimen and they vary in the opposite way. $K$ increases with the decrease of bulk density whereas $\Delta \mathrm{P}$ increases with the increase of bulk density. In gradient experiments, $\Delta \mathrm{P}$ is determined by the:rmal, gradient and porosity, whereas in TGA experiments $\triangle P$ is determined by the furnace temperature, heat flux and 


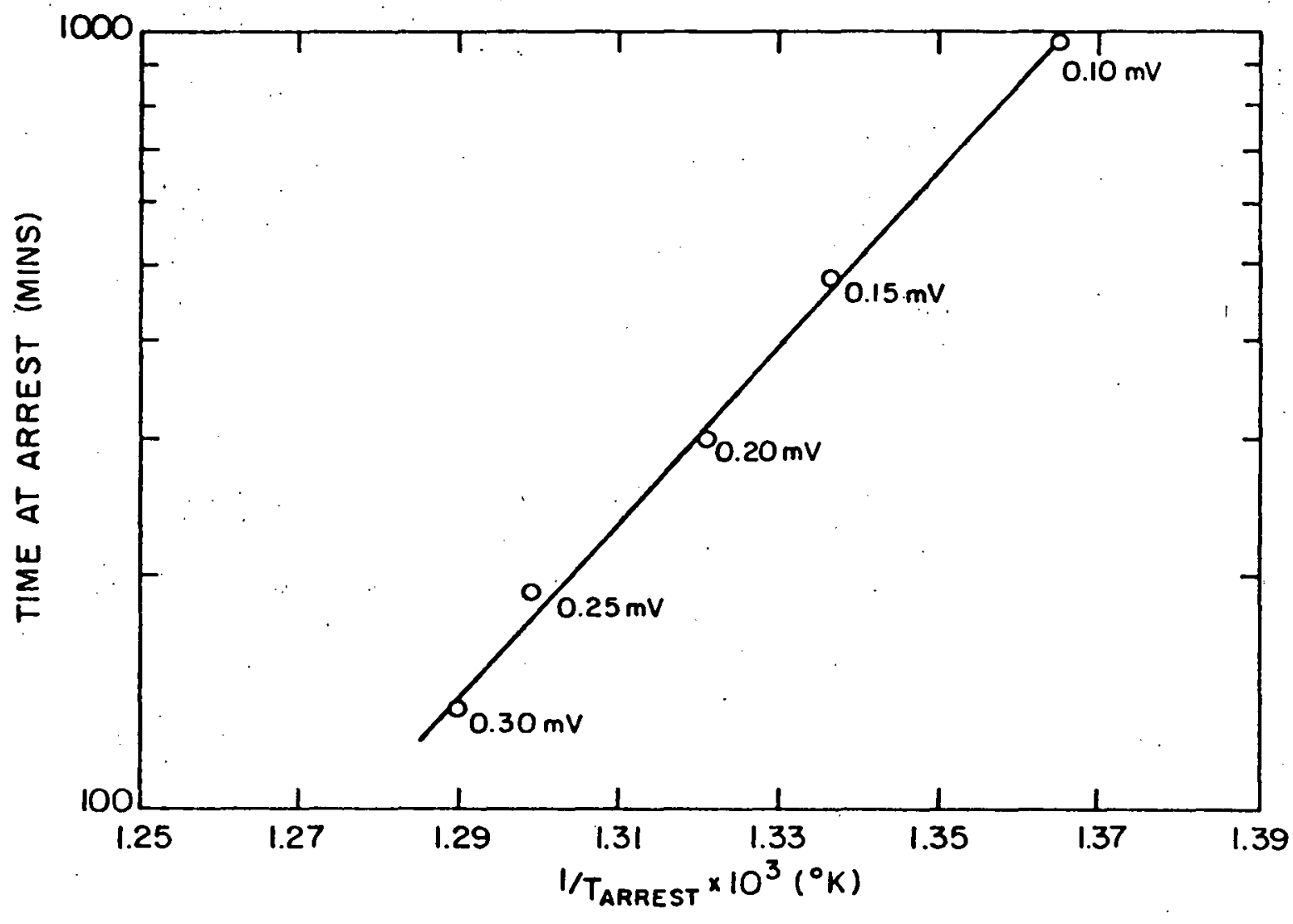

XBL $7012-7337$

Figure 4. Time at arrest vs. 1/T plot. $18 \mathrm{gs} .100 \% \mathrm{kaolin}$ specimens were used a.t varying thermal gradient. 
porosity. In a few experimental runs, furnace temperature was kept constant at $500^{\circ} \mathrm{C}$ and the variation of thermal gradient with time was recorded. The equilibrium thermal gradient for 18 gs $100 \%$ kaolin body was found to be $15^{\circ} \mathrm{C}$. Here it is to be noted that exactly similar conditions exist for 18 gs $100 \% \mathrm{kaol}$ in body in the gradient firing runs also (furnace temperature $490^{\circ} \mathrm{C}$, thermal gradient $15^{\circ} \mathrm{C}$ ). For 16 gs $100 \%$ kaolin sample it is expected that $500^{\circ} \mathrm{C}$ would be the equilibrium arrest temperature at a higher gradient than $15^{\circ} \mathrm{C}$ (as at $15^{\circ} \mathrm{C}$ thermal granient, $\left.T_{\text {arrest }}=470^{\circ} \mathrm{C}\right)$, which the conditions in the TGA experiment fails to maintain, thus reducing the thermal gradient from the equilibrium value and increasing the overall reaction rate. For 20 gs $100 \%$ kaol in sample, on the other hand, $500^{\circ} \mathrm{C}$ is the equilibrium temperature at a lower gradient than $15^{\circ} \mathrm{C}$, which the system tries to attain, thereby increasing the value of $\Delta \mathrm{P}$. Thus in FIg. 5 we see that $18 \mathrm{gs}$ sample dehydroxylates at the slowest rate, because in that case the combincd effect of permeation constant and the pressure gradient attains the minimum value. An arbitrary figure (Fig. 6) can be sketched which vill explain the above. K decreases with the increasc of density. But decrcaje of thermal gradient increases the $\Delta \mathrm{P}$ value exponentially, which we actually see for specimens weighing more than $18 \mathrm{gs}$. To establish the above hypothesis, more experimental evidence is necessary.

All the previous workers reported that loose specimens dehydroxylate fast. None of them uscd compact specimens and therefore effect of $\Delta P$ was practically negligible. Thus with increasing density, permeation constant varied only and therefore we would definitely expect the above result. In Fig. 7, dehydroxylation rate of three different 40 vol \% 


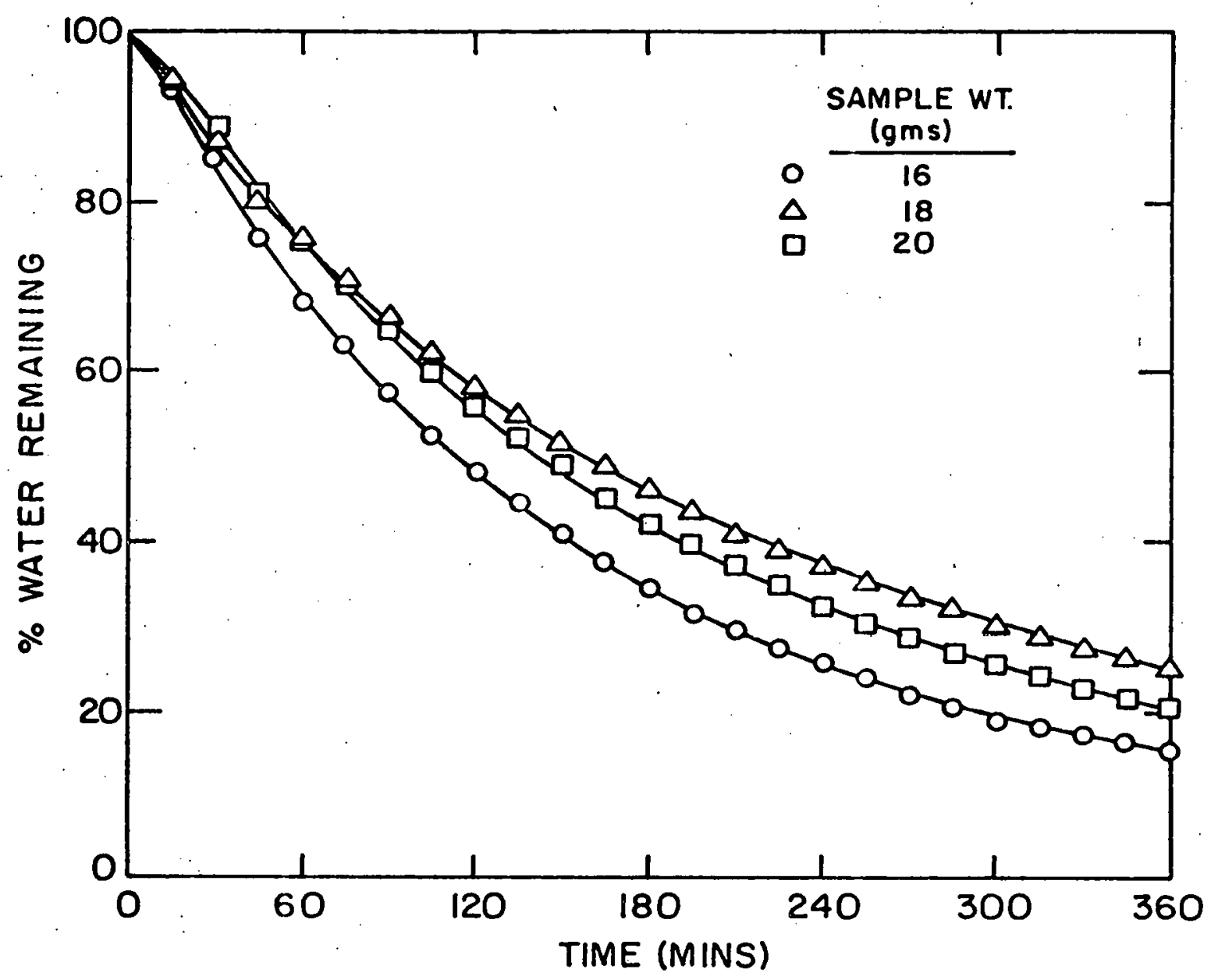

XBI $7012-7330$

Figure 5. TGA runs for varying bulk density specimens. $100 \%$ kaolin bodies were used. Temperature of experiment was $500^{\circ} \mathrm{C}$. 


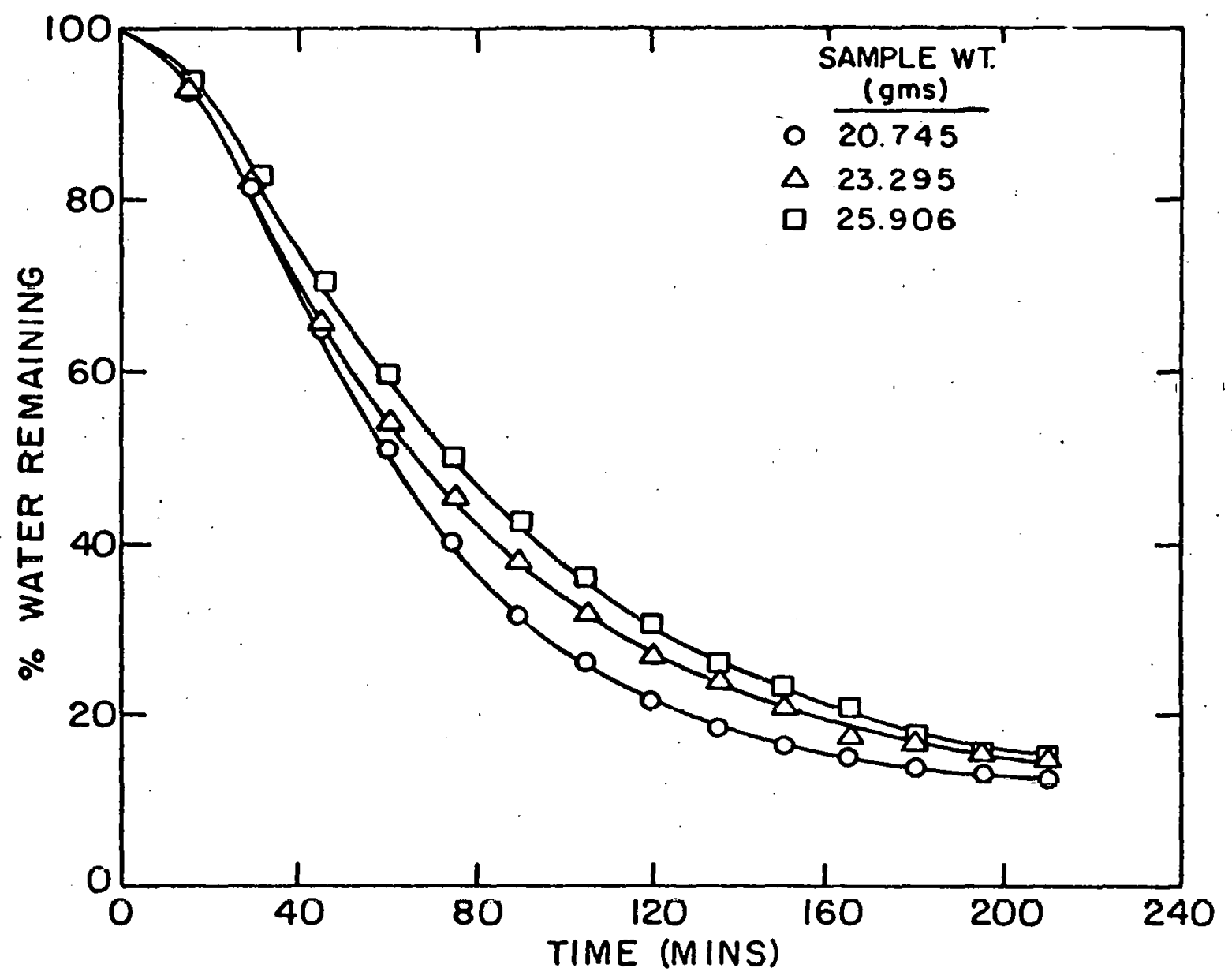

XBL $7012-7329$

Figure 6. TGA runs for varylng bulk density specimens. 40 vol \% clay bodica were used. Temperutury of experlment was $500^{\circ} \mathrm{C}$. 


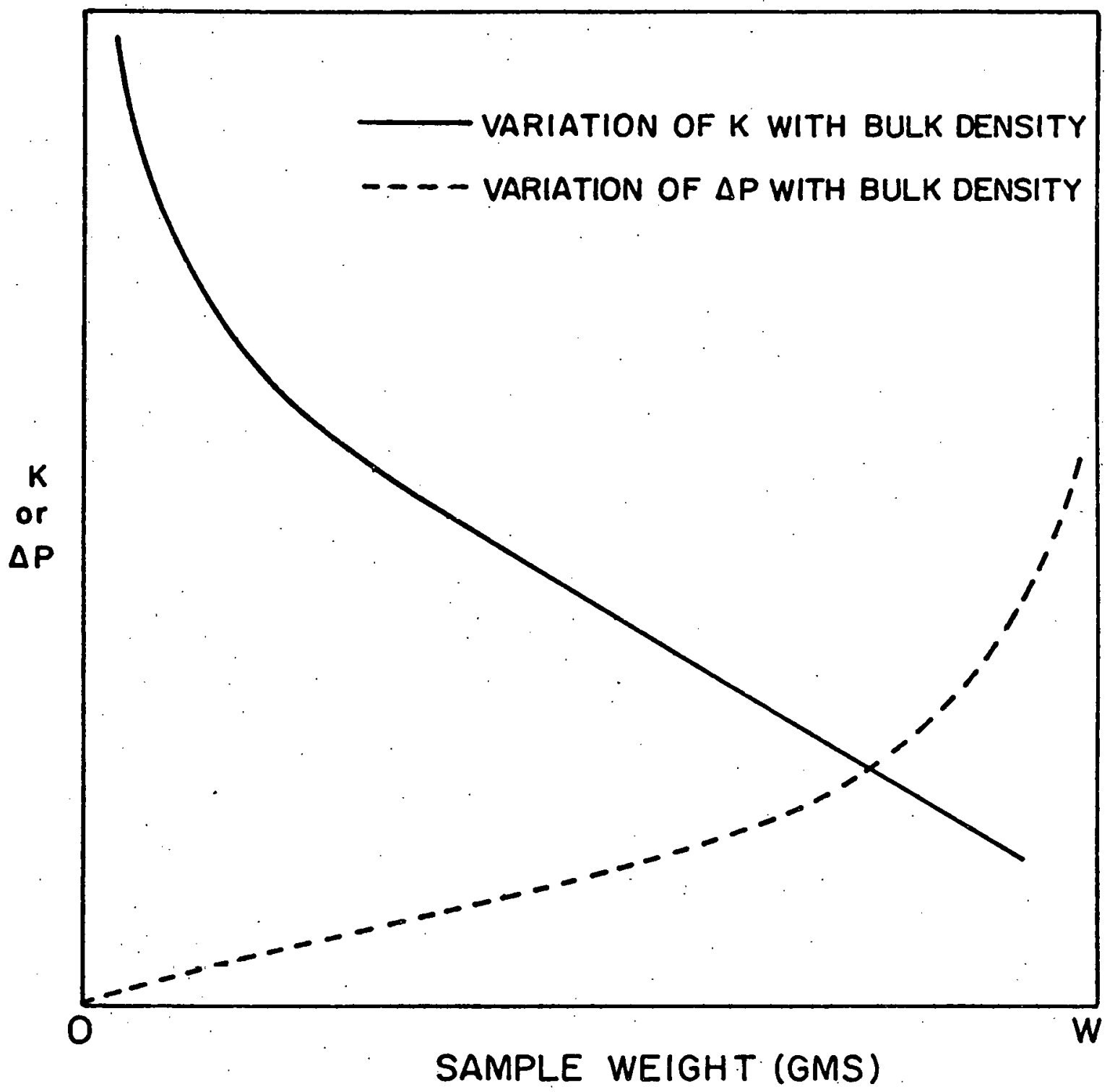

XBL $7012-7336$

Figure 7. Arbitrary plot showing variation of $K$ and $\Delta P$ with specimen weight when furnace temperature is constant. 
kaolin specimens, is shown. In this case, lowest bulk density specimen dehydroxylates at the fastest rate and the rate decreases with increasing bulk density. The reason is, in these specimens, the decrease of permeation constant with increasing density is much more important than the variation of $\Delta P$ because of the relatively small volume of water present. The same k1nd of reasoning, as given by Johnson and Kessler ${ }^{12}$ "with the increase in clay content reaction rate drops due to the blockA.ge nf grain boundary pathe, through which water prougly escapes, by both capillary condensation and water chemisorption on kaolinite surfacee," can aloo bc given if we ussume irner affrusion is actually the rate controlling step in the dehydroxylation of 40 vol \% kaolin specimens.

\section{Effect of Dilution of Clay Specimens with} Inert Alumina

In order to understand the actual processes going on in a compact. kaolin specimen during dehydroxylation, it is necessary to control the "gross diffusion" through the body. For these purposes, samples were prepared where a part of the clay was replaced by same volume of alumina. Both gradient firing and TGA rums were made with these samples. The important observations are:

(1) In the gradient experiments, the arrest temperature was always came at constant thermal bradicnt 1 rrespective of the alumina content. The time for dehydroxylation varied widely (Fig. 8).

(2) In the TGA runs reaction rate was higher for higher alumina containing bodies (Fig. 9). In all cases after about 75-80\% dehydroxylation the reaction rate dropped to about same value.

The fact that the arrest temperature did not change for varying 


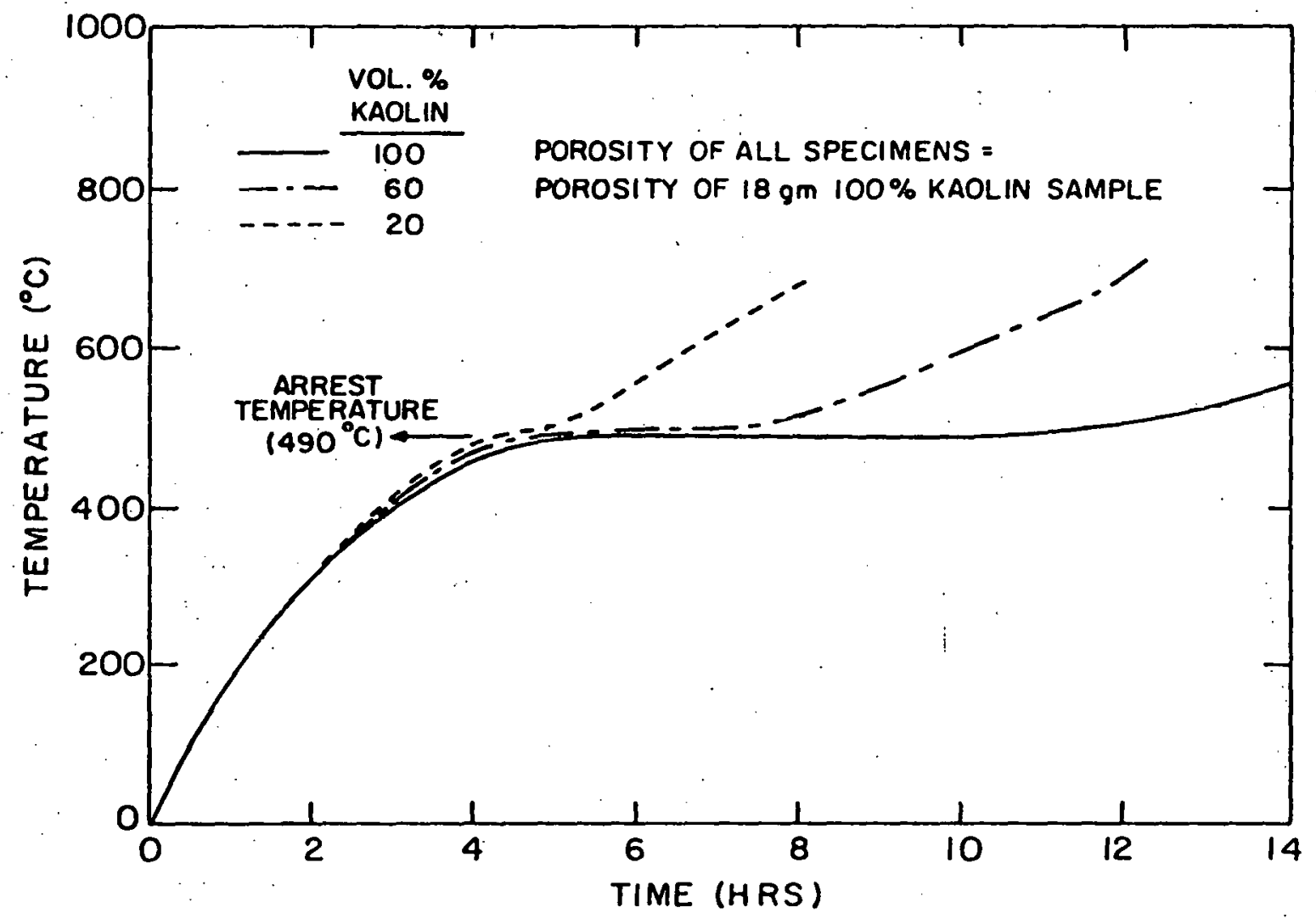

XBL $7012-7331$

Figure 8. Thermal gradient runs for varying alumina containing specimens. Gradient vas $0.15 \mathrm{mV}$ in all cases. 


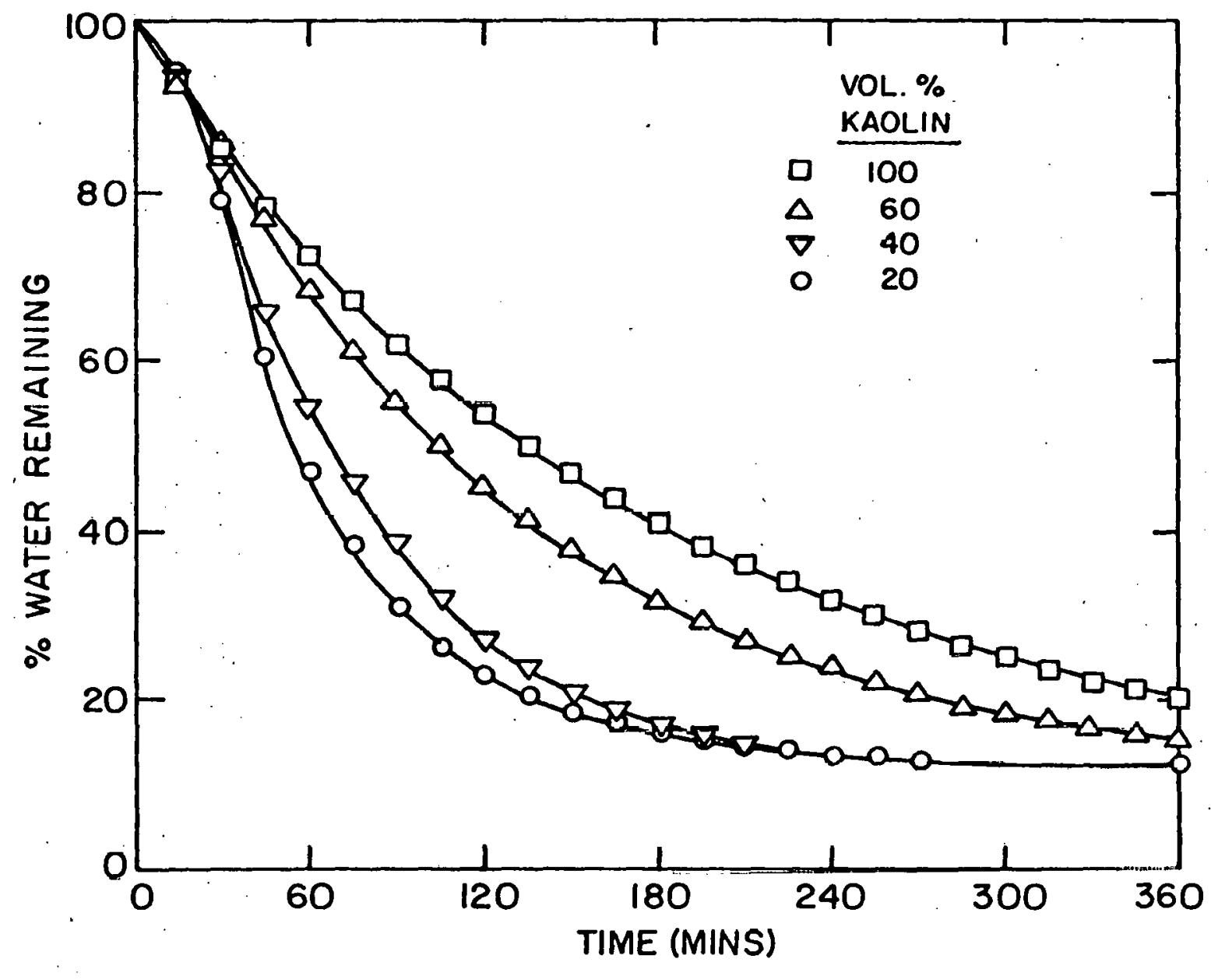

$X B L 7012-7332$

Figure 9. TGA runs for varying alumina containing specimens. Porosity In all specimens was equal to that in 18 ens. $100 \%$ kaolin sample. Temperature was $500^{\circ} \mathrm{C}$. 
alumina containing bodies of same size and porosity when the set gradient was canstant confirms the hypothesis of an "equilibrium back pressure" and proves its dependence on porosity and thermal gradient.

Since the arrest temperature and hence back pressure was constant in all these gradient runs, we would expect from Eq. (9)

$$
\frac{d w}{d t}=A \cdot K \cdot \Delta P
$$

that for specimens of same porosity (same $K$ ), dw/dt is constant at the arrest portion. On integration we get

$$
\mathrm{W}_{\text {arrest }}=\mathrm{C} \cdot \mathrm{t}_{\text {arrest }}+\mathrm{C}_{\mathrm{O}}
$$

where $W_{\text {arrest }}=$ weight lost at the arrest portion, $t_{\text {arrest }}=$ time at the arrest portion, $c=a$ constant $=A k . \Delta P$ and $C_{0}=$ another constant. But when $t_{\text {arrest }}=25$ minutes, $\mathrm{w}_{\text {arrest }}=0$. This is because $100 \%$ alumina body takes 25 mins. to move through ( $\left.\mathrm{T}_{\text {arrest }}-20^{\circ} \mathrm{C}\right)$ to $\left(\mathrm{T}_{\text {arrest }}+20^{\circ} \mathrm{C}\right)$. Therefore

$$
\begin{aligned}
& c_{0}=-25 c \\
& W_{\text {arrest }}=r\left(t_{\text {arrest }}-25\right)
\end{aligned}
$$

Table I shows the amount of water expelied at the arrest temperature $\left(490 \pm 20^{\circ} \mathrm{C}\right)$ for varying alumina containing bodies and Fig. 10 shows the straight line relationship between $W_{\text {arrest }}$ and $\left(t_{\text {arrest }}-25\right)$. 
$-26$

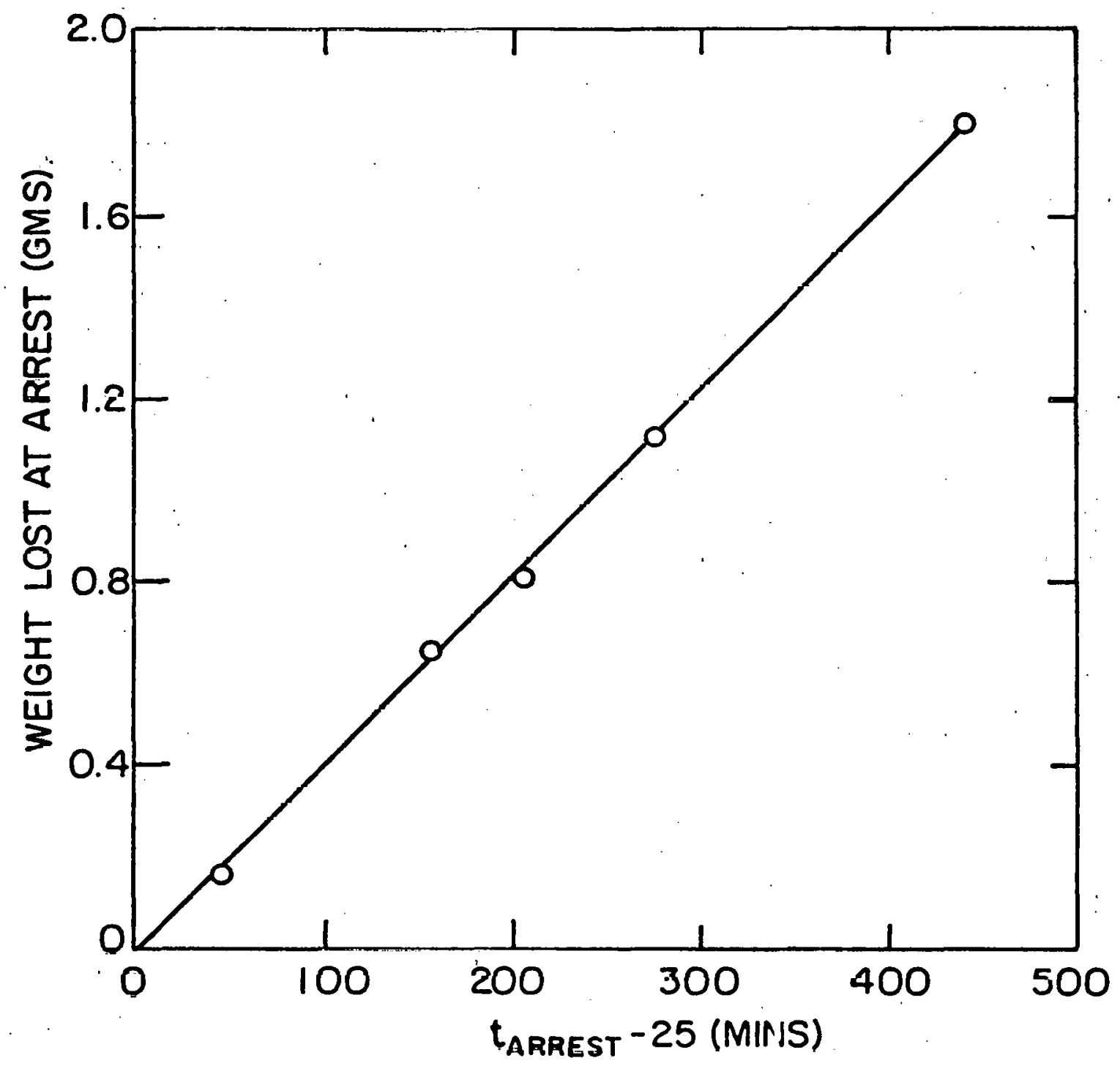

XBL 7012-7333

Figure 10. Relation between $W_{\text {arresl }}$ and $t$ arrest for varying alumina containing suecisens. Tarrest was $490^{\circ} \mathrm{C}$ and thermal gradient vai $0.1 .5 \mathrm{mV}$. 
Table I. (T arrest $\left.=490^{\circ} \mathrm{C}\right)$

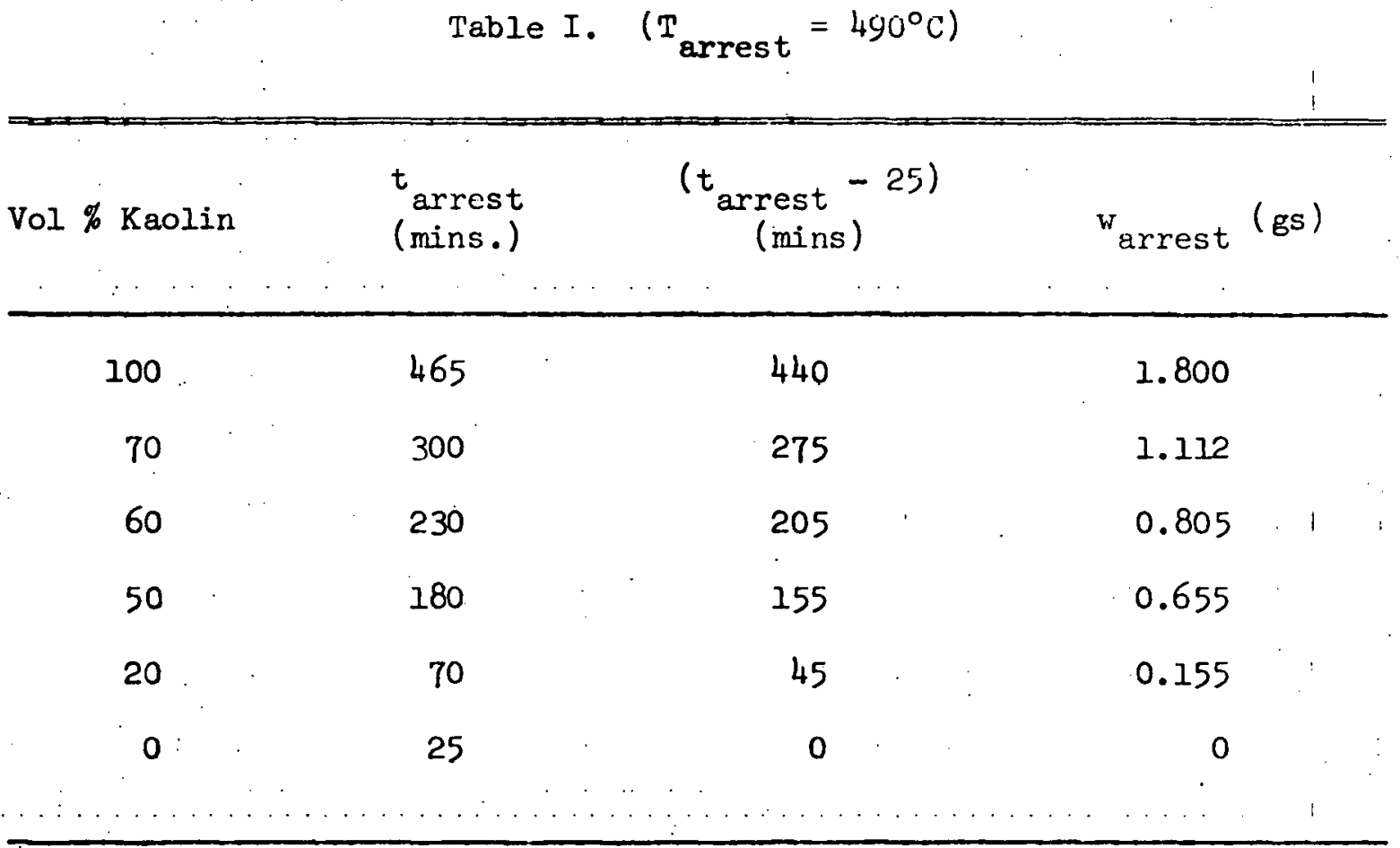

Increase in alumina content in the body reduces the total amount of water vapor to be expelled. We would therefore expect a decrease of $t$ arrest with increasing alunina, as dw/dt was constant for all clayalumina specimens. We observe the same fact in Fig. 8.

In the TGA runs, porosity was same in all the specimens. Furnace temperature was always kept constant at $500^{\circ} \mathrm{C}$. So in every case the system would try to attain the same back pressure. But total water content was varying. So naturally sampies containing high alumina, which contain less water, would dehydroxylate fast as we observe in Fig. 9.

\section{Mechanism}

Johnson and Kessler ${ }^{12}$ in their studies on dehydroxylation of haolinite used thin pastes of samples brushed on the sides of the platinum sceen and their conclusion was the reaction proceeds by a 
pseudo-phase boundary controlled reaction in the [001] direction of the polycrystalline particles. Their experimental conditions avoid the com-plications due to "gross diffusion" of water vipor. In large compact specimens, on the other hand, if volume of water vapor to be expelled is quite large, "gross diffusion" step may behave as the slow step rather than the phase boundary controlled reaction in the individual kaolinite particles. But if volume of water to be expelled is small enough, such that the flux of water vapor coming out of the body is larger than the amount produced in unit time, then it is expected that the same mechanism as suggested by Johnson and Kessler ${ }^{12}$ would be rate controlling irrespective of the size and porosity of the samples. So two different slow steps may control the reaction rate in high alumina containing bodies and in low alumina containing bodies. In Fig. 11, \% water remaining has been plotted against $t / t_{0}{ }_{5}$ for various TGA runs, where $t_{0.5}$ is the time for $50 \%$ dehydroxylation. It is interesting to note that up to $50 \%$ dehydroyxlation all the data points fall on the same line, except those for 40 vol \% kaolin and 20 vol \% kaolin bodies. The variables introduced by the composition and structure have been included hy usiubs $t / t_{0.5}$ instead of $t$, but still the different path followed by 40 and $20 \%$ kaolin bodies definitely points out that a different slow step followed by them. Furthermore, it has been observed that at the later stage of dehydroxylation the rate becomes more or less same in all cases, which means that at this later part of the reaction, the amount of water remaining was always small and thus probably this stage of the reaction is always controlled by the "pseudo-phase boundary controlled reaction." 


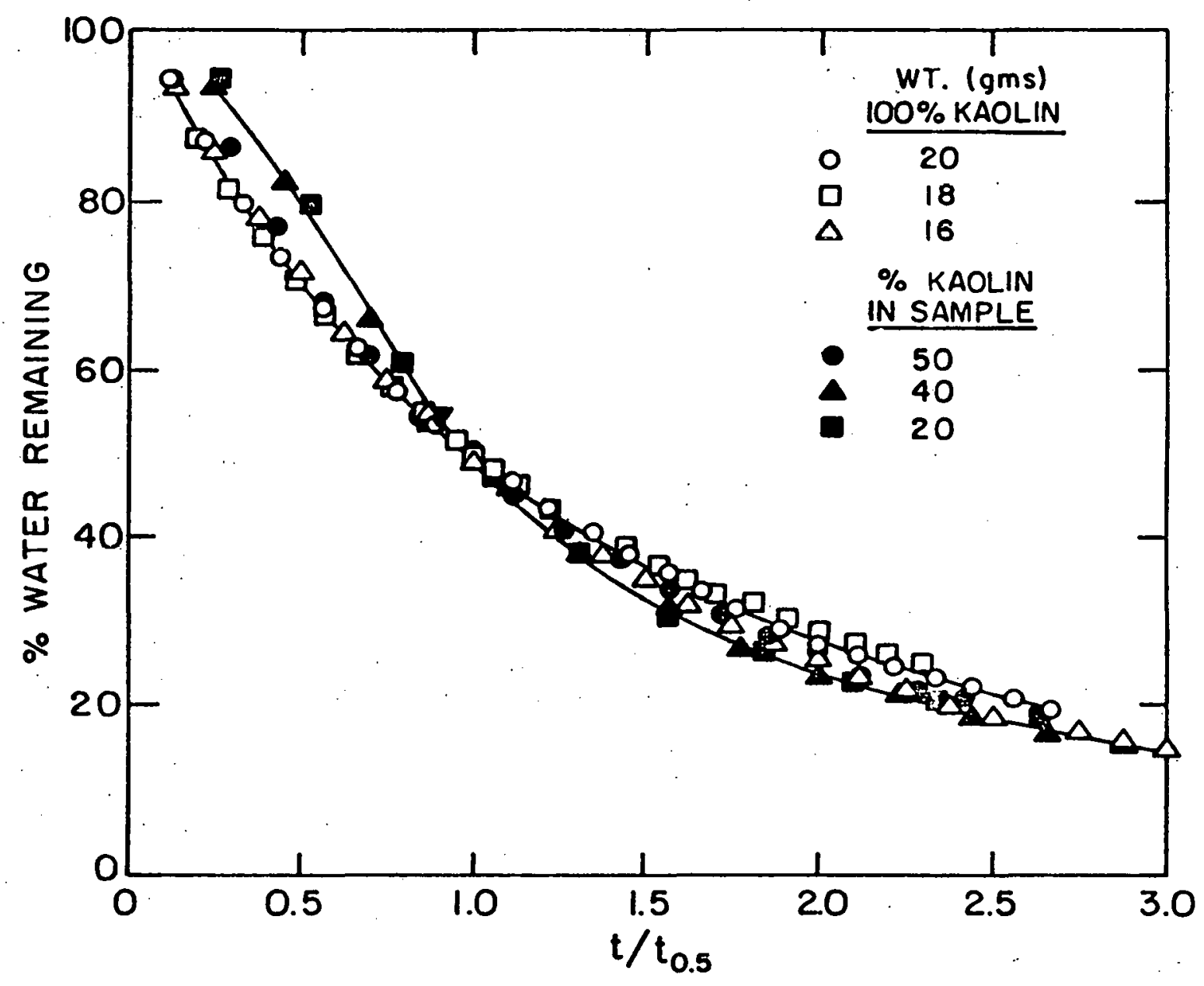

XBL $1012-7334$

Figure 11. Reduced time plot from TGA runs for various samples. Temperature of experiment was $500^{\circ} \mathrm{C}$. 
This difference in slow step for the high and low alumina containing bodies has also been observed in the gradient runs. Figure 12 shows the relation between vol \% kaolin and tine at arrest. A change in slope at about 40 vol \% kaolin clearly indicates a change in the basic slow step. 


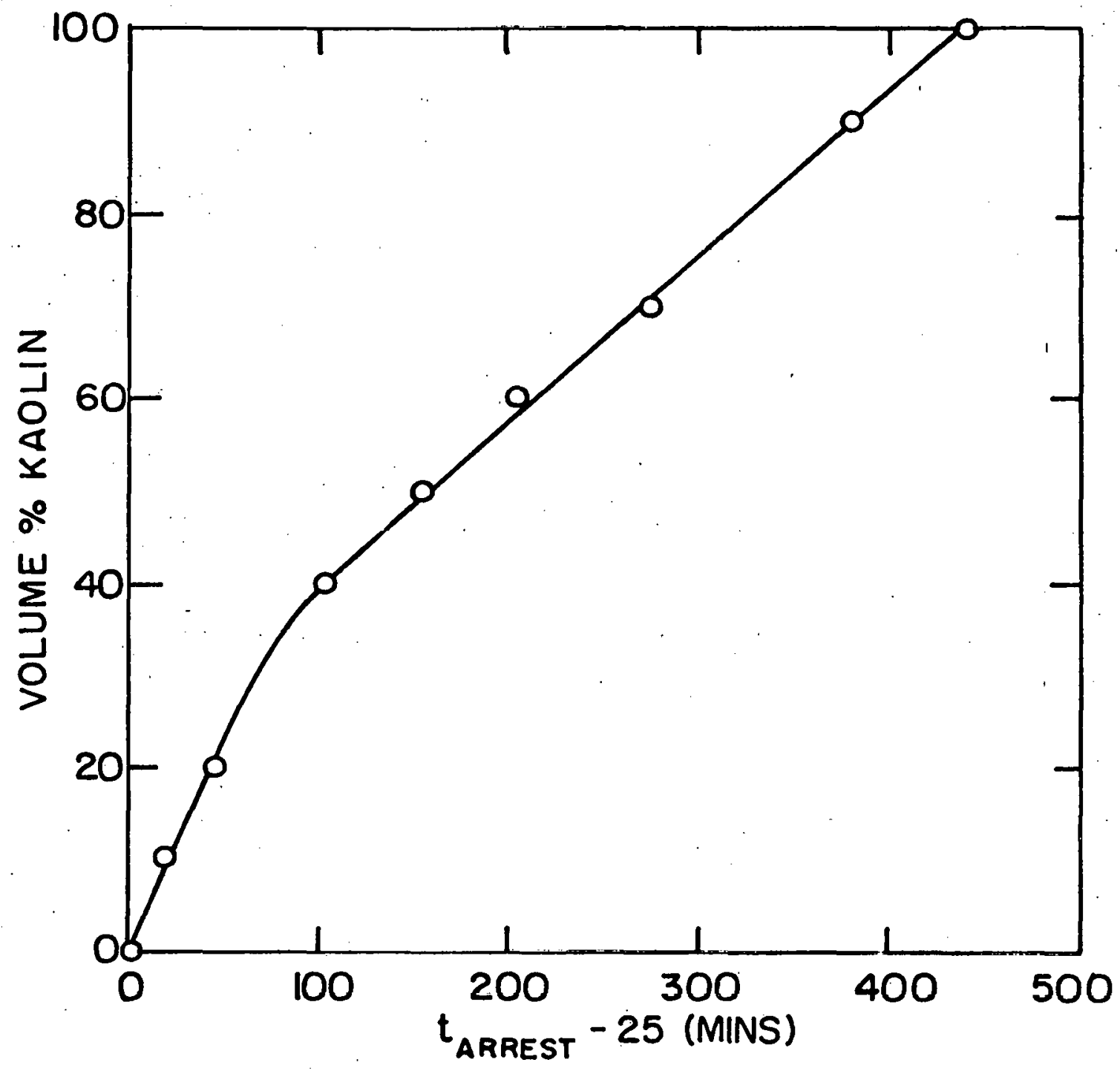

XBL $7012-7335$

Figure 12. Relation between vol \% kaolin and time at arrest. 'lhermal gradient was $0.15 \mathrm{mV}$. 


\section{SUMMARY AND CONCLUSION}

Kaolinite dehydroxylation reaction on compact specimens has been studied by gradient firing technique and thermogravimetric analysis. Gradient firing technique is a new analyzing method where the main control is a fixed temperature gradient through the specimen. The following conclusions have been made:

(1) Porosity and thermal gradient determine an "equilibrium back pressure" in the gradient firing runs, which actually determine the reaction temperature. Increasing thermal gradient and decreasing porosity increase the equilibrium back pressure, The reaction rate is determined by a combined effect of permeability and back pressure.

(2) In TGA, the set furnace temperature mainly controls the process. In this case also, the reaction rate is determined by a combined effèct. of permcability and back pressure. It has been observed that the reaction rate is minimum for the specimen which undergoes decomposition in perfectly equilibrium condition. In other. words, the set temperature, porosity, heat flux and thermal gradient are related to each other in a way that was existing in the gradient firing run for the. came opceimen.

(3) In a few specimens, a part of clay was replaced by an equal volume of inert alumina in order to control the permeation of water vapor through the porous mass. Both thermogravimetric and gradient firing experiments were done with these specimens. In the gradient runs for these specimens, a constant arrest temperature was always obtained irrespective of the alunina content in the body, which gives a conclusive proof about the dependence of dehydroxylation process on the 
porosity and thermal gradient and also confirmed the hypothesis of equilibrium back pressure.

(4) It has been concluded that two different slow steps, namely permeation and the reaction step, may control the dehydroxylation process lepending on the porosity, temperature of the reaction, and the total amount of water content in the body. In corpact specimens and in the temperature range at which the present study was carried out, the permeation of water vapor seems to control the process in most cases. In cases where total amount of water present in the body was too small, for example in high aluminum containing bodies, reaction step was found to control the process. 


\section{ACKNOWLEDGMENT}

The author wishes to thank Professor R. M. Fulrath and Professor

J. A. Pask for their help and guidance in this work.

This work was done under the auspices of the Uni led States Atomic Energy Commission. 


\section{REFERENCES}

1. R. Roy and G. W. Brindley, "A study of the hydrothermal reconstitution of the kaolin mineral," p. 125-132, Clay and Clay Minerals, Proc. 4th Natl. Conf. 1955.

2. G. W. Brindley and M. Nakahira, "Role of water vapor in the dehydroxylation of kaolin minerals," Clay Minerals Bull.; 3 , $114-19$ (1957).

3. G. W. Brindley and M. Nakahira, "Kinetics of dehydroxylation of kaolinite and halloysite," J. Am. Ceram. Soc.; 40, 346-50 (1957).

4. J. L. Evans and J. White, "Further studies of the thermal decomposition (dehydroxylation) of clays," Trans. Brit. Ceram. Soc., 57, 289-311 (1958).

5. F. Tursaint, J. J. Friforat and M. C. Gastache, "Dehydroxylation of kaolinite, I Kinetics," J. Phys. Chem., 67, 26-30 (1963).

6. J. B. Holt, I. B. Cutler and M. E. Wadsworth, "Rate of thermal dehydration of kaolinite in vacuum," J. Am. Ceram. Soc., 45, 133-36 (1962).

7. P. Murray and J. White, "Kinetics of thermal dehydration of Clays I," Trans Brit. Ceram. Soc.; 24, 137-50 (1955); II, p 151-87; III, p 189-203, IV, p 204-38.

8. J. N. Weber and R. Roy, "Dehydroxylation of kaolinite, dickite and. halloysite: Heats of reaction and kinetics of dehydration at $\mathrm{P}_{\mathrm{H}_{2} \mathrm{O}}=15$ psi," Am. Mineralogist, 50, 1038-45 (1965).

9. G. W. Brindley, J. H. Sharp, J. H. Patterson and B. R. Narahariachar, "Kinetics and mecharisms of dehydroxylation process," Am. Mineralogist, 52, 201-11 (1967). 
10. J. H. Sharp, G. W. Brindley and B. N. Narahariachar, "Iumerical data for some commonly used solid state reaction equations, J. Am. Ceram. Soc. $49,379-82(1966)$.

11. R. E. Carter, "Kinetic model for solid state reactions," J. Chem. Phys., 34, 2010-15 (1961).

12. H. B. Johnson and F. Kessler, "Kaolinite dehydroxylation kinetics," J. Am. Ceram. Soc., 52, 199-204 (1969).

13. R. M. Fulrath, personal communication.

14. Advertisement in Am. Ce ram. Soc. Bull., 46 (1970). 


\section{LEGAL NOTICE}

This report was prepared as an account of Government sponsored work. Neither the United States, nor the Commission, nor any person acting on behalf of the Commission:

A. Makes any warranty or representation, expressed or implied, with respect to the accuracy, completeness, or usefulness of the information contained in this report, or that the use of any information, apparatus, method, or process disclosed in this report may not infringe privately owned rights; or

B. Assumes any liabilities with respect to the use of, or for damages resulting from the use of any information, apparatus, method, or process disclosed in this report.

As used in the above, "person acting on behalf of the Commission" includes any employee or contractor of the Commission, or employee of such contractor, to the extent that such employee or contractor of the Commission, or employee of such contractor prepares, disseminates, or provides access to, any information pursuant to his employment or contract with the Commission, or his employment with such contractor. 
TECHNICAL INFORMATION DIVISION

LAWRENCE RADIATION LABORATORY UNIVERSITY OF CALIFORNIA

BERKELEY, CALIFORNIA 94720 